\title{
RÁDIO A SERVIÇO DA COMUNIDADE ${ }^{1}$
}

\section{Programa de rádio Sáude no ar, iniciativa do Ministério da Sáude, teve colaboração de emissoras comerciais e de alto-falantes na prestação de serviços às comunidades carentes do Nordeste}

O rádio é, hoje, parte integrante do cotidiano da grande maioria da população brasileira. Estima-se que, em média, $90 \%$ da população de baixa renda, homens e mulheres de todas as idades, ouvem a programação radiofônica por cerca de três horas diárias, segundo dados da Marplan (1992).

Pesquisa realizada pela Datafolha, na Grande São Paulo, em dezembro de 1993, revelou que as pessoas, independentemente da classe social a que pertencem, passam mais tempo ouvindo rádio do que assistindo a televisão, lendo jornais ou revistas. A audiência diária do veículo concentra-se no período de 8 às 18 horas, enquanto a da TV restringe-se ao horário de 19 às 22 horas.

A grande popularidade do veículo é atribuída ao caráter universal de sua linguagem essencialmente coloquial, simples e direta além da empatia que procura estabelecer com o ouvinte ao atender suas demandas por lazer, música, entretenimento, informação e companhia. A audição do rádio pode ser feita em qual-

\section{A AUTORA}

\section{Nélia R. del Bianco}

Professora da Faculdade de Comunicação da Universidade de Brasília e executora do convênio PNUD/UnB que objetiva o desenvolvimento do projeto Saúde no Ar. quer lugar, sem dependência de tomadas ou fios, e serve como fundo sonoro ao ouvinte ocupado com alguma outra atividade. Por essas características, o veículo é parte fundamental de qualquer projeto de educação em saúde que objetive atingir a população de baixa renda e carente de informação. Consciente de sua importância, a Coordenação de Informação, Educação e Comunicação - IEC, do Ministério da Saúde, componente do Projeto Nordeste, financiado pelo Banco Internacional para Reconstrução e Desenvolvimento (BIRD) - elaborou o programa Saúde no ar como um elemento adicional de sua estratégia de educação e de comunicação para a saúde.

Para pensar e definir o programa quanto ao formato, linguagem, estilo e gênero, fez-se necessário rever e avaliar as experiências anteriores que utilizaram o veículo em processos educativos. Só assim se pode evitar a repetição de erros e fracassos, pois, no Brasil, a história do rádio educativo é reveladora de uma série de equívocos que precisam ser superados.

\section{RÁDIO E EDUCAÇÃO NO BRASIL}

Historicamente, no Brasil, rádio e educação sempre estiveram associados. Roquete Pinto, fundador da primeira emissora no País, 
Rádio Sociedade do Rio de Janeiro, defendia a transmissão de educação e cultura pelo rádio como estratégia para reduzir os elevados índices de analfabetismo. Ao colocar em prática sua tese, contudo, não atingiu o objetivo de popularizar o conhecimento. Isto deveuse ao fato de que a programação educativa produzida pela sua emissora, na década de 20 , era recheada de palestras científicas e literárias, acessíveis apenas a um público seleto, àquele que tinha recursos para adquirir um aparelho receptor importado.

A preocupação educativa de Roquete Pinto originou uma série de outras iniciativas - escolas radiofônicas, por exemplo - que surgiram, posteriormente, sob o controle do Estado, universidades ou instituições, com o objetivo de transmitir conhecimento e instrução básica.

A maioria dos programas educativos lançados $^{2}$ reproduzia o ambiente da sala de aula, com cursos regulares de Matemática, Português e Ciências, totalmente distanciados do universo simbólico e cultural de seu público-alvo.

A exceção à regra foi a experiência desenvolvida pelo Movimento de Educação de Base (MEB), na década de 60, que, através de escolas radiofônicas, alfabetizava adultos e crianças e cuidava da conscientização para promover mudanças de atitudes, utilizando, para tanto, animadores populares que organizavam audições nas comunidades.

$\mathrm{O}$ fracasso das experiências de educação massivo-instrucional pelo rádio, evidenci- ado pelo baixos índices de audiência, demonstrou que esse meio não constitui um espaço adequado para exercer a educação formal. Segundo Burgos, a utilização do rádio não é ideal para educar, no sentido formal, porque na vida cotidiana das pessoas ele é percebido e utilizado como lazer e entretenimento nos intervalos entre o trabalho e os afazeres domésticos ${ }^{3}$.

Com o objetivo de superar as experiências anteriores surgiu, na década de 70 , o Projeto Minerva, programa radiofônico governamental de 30 minutos, de cunho informativo-cultural e educativo, de transmissão obrigatória em nível nacional. O programa, no entanto, também não conquistou o prestígio da audiência, por vários motivos: sua produção era regionalizada - ficava a cargo da Fundação Educacional Padre Landell de Moura (FEPLAN-RS) e da Fundação Padre Anchieta (SP) - e sua distribuição centralizada.

A regionalização, que poderia ser a marca do sucesso, não funcionou porque se concentrou no eixo Sul-Sudeste e, evidentemente, com tal característica, não respondia à diversidade cultural (costumes, língua $\mathrm{e}$ modo de vida), nem às necessidades e interesses de cada região do país. A experiência revelou-se negativa e contribuiu para fortalecer a idéia de que rádio educativo é chato, cansativo e desagradável.

\section{EDUCAÇÃO POPULAR}

À margem do educativo institucional, setores organizados da sociedade civil começaram a utilizar o rádio, na década de 80 , com

2. Entre os quais podemos citar o programa Universidade no Ar, lançado em 1941 pela Rádio Nacional do Rio de Janeiro, e os cursos básicos do Sistema de Rádio Educativo Nacional - Sirena, veiculados no período de 1957-63. Ler mais sobre o ensino pela radiodifusão no mundo em: White, Robert A. Ensino a distância: experiências e inovações. Comunicação \& Educação. n. 3, maio/ ago. 1995. p. 47-56.

3. BURGOS, C.C. Os novos usos do rádio: o cultural e o educativo postos em questão. In: SOARES, Ismar de O. , MOTTA, J. M.

A comunicação na construção da paz. São Paulo: Paulinas, 1987. p. 91-97. 
propósitos cultural e político, dando novo sentido a esses processos. São experiências em que organizações populares e sindicais passaram a manejar e controlar meios tecnológicos para transmitir suas mensagens nas denominadas rádios livres ou rádios populares por alto-falantes. Além do caráter libertador de suas mensagens, esses setores mostraram novas e criativas formas de expressão e intercomunicação social, como a recriação da notícia, a recuperação da história oral da comunidade e a dramatização de situações do cotidiano. Elas contribuíram, segundo Burgos, para repensar a comunicação a partir do popular - aqui entendido como o lugar a partir do qual se torna possível abarcar e compreender o sentido que adquirem os processos de comunicação para a audiência.

Pelo viés do popular, o cultural e o educativo ganharam outro sentido, distinto daquele vinculado à concepção erudita $\mathrm{e}$ formal predominante em produções radiofônicas ditas educativas, direcionadas à alfabetização e à difusão de conhecimentos.

A produção educativa passa a ser direcionada à transmissão de valores, promoção humana, desenvolvimento integral do homem e da comunidade, servindo de estímulo à reflexão e à transformação social ${ }^{4}$.

$\mathrm{Na}$ base dessa mudança está implícita uma nova forma de definir cultura. Cultura passa a ser entendida como o oposto à idéia de mera acumulação de saber a ser cultuado e pre- servado, sendo assim um espaço de conflito que reflete a própria dinâmica social. É uma forma de viver dentro da sociedade, que engloba todos os significados da experiência social $^{5}$. Portanto, no conceito de cultura estão englobados quer "os significados e valores que surgem e se difundem nas classes e grupos sociais, quer as práticas efetivas através das quais esses valores e esses significados se exprimem e nas quais estão contidos" 6 .

Nessa perspectiva, a comunicação não é mero instrumento de transmissão de conhecimentos, mas processo cultural que agrega conflitos, contradições sociais e as práticas dos movimentos populares ${ }^{7}$.

A nova dimensão do cultural/educativo no rádio aproxima o popular do massivo. Segundo Martín-Barbero ${ }^{8}$, é necessário pensar o massivo em seu interior, abandonando velhas concepções reducionistas como, por exemplo, a que vê a ação dos meios de comunicação como elemento de desagregação da cultura ou aquela que não acredita na capacidade de as classes populares produzirem cultura. $\mathrm{O}$ autor propõe pensar o massivo como uma nova forma de sociabilidade, que reflete e articula novas condições de existência e luta, ou seja, um novo modo de funcionamento da hegemonia.

Tal visão implica, necessariamente, na compreensão do sistema de representações e imagens com as quais as classes populares decodificam os produtos simbólicos. Trata-se, assim, de uma relação mais complexa do que as teorias relativistas imaginam, não podendo ser resumida na velha e gasta explicação de que os meios de comunicação são alienantes.

4. KAPLÚN, Mário. Producción de programas de radio: el guión, la realización. Quito: CIESPAL, 1978.

5. FISKE, J. Bristish Cultural Studies and television (Televisão e os estudos culturais britânicos). In: ALLEN, R. (ed.) Channels of discourse. U. Of. Nort Caroline Press: Chapel Hill. 1987.

6. WOLF, M. Teorias da Comunicação. Lisboa: Presença, 1987. p. 94.

7. Ver mais sobre esta discussão em: PAULINO, Roseli A. Fígaro. Estudo de recepção: o mundo do trabalho como mediação da comunicação. São Paulo, ECA - USP, 1999. (Tese de Doutorado.) (N. Ed.)

8. MARTIN-BARBERO, J. La comunicación desde la cultura: crisis de lo nacional y emergencia de lo popular. (A comunicação a partir da cultura: crise de nacional e emergência do popular) Cultura \& Sociedade. São Bernardo do Campo, São Paulo: Imes, n. 13. julho 1985. 
Nesse sentido, há um estudo significativo realizado por Maria Immacolata Lopes. Ela analisou diversos programas policiais ${ }^{9}$ veiculados em emissoras paulistas, dirigidos à população marginal, e concluiu que essas narrativas não são totalmente alienantes e de evasão. Ao contrário, são profundamente ambivalentes. Elas reforçam e reproduzem o conflito latente entre a marginalidade e o sistema que a produz. Referem-se às condições de vida, particularizam as dificuldades cotidianas das classes marginalizadas e produzem efeitos ideológicos que podem mobilizar tanto para condutas de consumo como para reações de inconformismo.

É nesse campo teórico, livre de concepções maniqueístas quanto ao uso da comunicação em processos educativos, que $o$ projeto do programa radiofônico Saúde no $A r$ foi pensado e articulado.

Com o propósito de integrar o educativo/ cultural ao popular, o projeto buscou inspiração no trabalho atualmente desenvolvido por produtores de rádio comercial, os quais, em geral, desenvolvem melhor as instâncias educativas nãoformais porque entendem a dinâmica da narrativa popular. Basta observar as programações das emissoras para verificar que seus discursos contêm elementos de drama, afeto, amizade, humor, solidariedade e esperança de mudança, fatores integrantes do universo cultural das chamadas classes populares ${ }^{10}$. Enfim, elas captam a densidade e a diversidade de condições de existência do popular.

\section{SAÚDE NOAR: CONQUISTA DO PÚBLICO}

Como foi visto, os programas educativos institucionais, em geral, são considerados aborrecidos, de conteúdo parcial, meramente de propaganda governamental, em formato e estilo diferenciados dos padrões do rádio comercial e, o pior, sem periodicidade regular de produção e distribuição. Tê-los como parte de uma programação é sinônimo de baixos índices de audiência, e nenhuma emissora arriscaria seu prestígio levando ao ar algo de qualidade duvidosa. A resistência aos mesmos aumenta, principalmente quando sua veiculação é obrigatória, sem permitir qualquer espaço para o programador definir o horário mais conveniente aos interesses da emissora.

\section{Desafios}

Superar esse estigma era o principal desafio a ser enfrentado na produção do Saúde no ar. Tanto a Coordenação do IEC quanto a Faculdade de Comunicação da Universidade de Brasília, executora do convênio que viabilizou o projeto, decidiram vencer a falta de credibilidade, propondo realizar um programa de formato ágil e dinâmico, com excelente qualidade técnica de mixagem e de gravação, explorando o potencial da linguagem do meio com o uso de recursos variados, da dramatização a entrevistas com médicos, enfermeiros, agentes comunitários de saúde e população. Qualidade, antes de tudo, foi a marca registrada do Saúde no ar, característica considerada fundamental para a conquista do público e a adesão das emissoras de rádio.

9. LOPES, Maria Immacolata V. Sensacionalismo e estereótipos na cultura de massa-programa policial de rádio e populações marginais. In: SOARES, I de O. , MOTTA, J. M. A Comunicação na construção da paz. São Paulo: Paulinas, 1987.

10. O termo classes populares refere-se a grandes contingentes de baixa renda, de composição heterogênea: operários, ambulantes, empregados em todos os ramos de serviço, que, apesar de indefesos, guardam a capacidade de reclamar a igualdade no recebimento de benefícios sociais. O conceito é meramente descritivo mas permite ver a capacidade de manifestação concreta das classes. 
Elemento-chave nessa estratégia era a regionalização da linguagem e do conteúdo, tarefa difícil de ser concretizada, a princípio, em ações centralizadas, devido aos elevados custos de produção.
Nesse caso, havia um elemento facilitador que possibilitou plenamente essa aproximação: em cada Estado brasileiro há uma coordenação de IEC com uma equipe multidisciplinar, constituída por médicos, enfermeiros, assistentes sociais, pedagogos e jornalista. Esse pessoal foi incorporado à equipe de produção para realizar, mensalmente, entrevistas com profissionais de saúde, agentes comunitários e população sobre os temas pautados. As fitas gravadas eram enviadas a Brasília, via correio, onde eram editadas e incorporadas ao produto final. As entrevistas foram um dos elementos mais positivos do programa, por estabelecerem ligação com o universo simbólico cultural da região, possibilitando a ilustração dos temas com situações vivenciadas no cotidiano da população.

\section{Princípios}

Para criar o formato do programa educativo era necessário definir um princípio norteador para a abordagem das questões de saúde. Após algumas discussões realizadas, e em consonância com os princípios teóricos do projeto, ficou definido que o Saúde no ar partiria do entendimento de que saúde é resultante das condições de vida, alimentação, habitação, educação, renda, meio ambiente, trabalho, transporte, emprego e acesso aos serviços de saúde. Por isso, a geração de novas atitudes e procedimentos frente aos problemas de saúde deve ser vista como uma missão de todos, esforço coletivo, e não apenas como uma obrigação governamental. Para promover tal mudança de comportamento é fun- damental que a população compreenda as origens, as causas sociais, políticas e econômicas geradoras de doenças na região Nordeste.

Com base nesse pressuposto, as mensagens do programa deveriam ser produzidas dentro dos seguintes critérios:

a) ilustrar os problemas de saúde a partir de situações vivenciadas no cotidiano do público-alvo;

b) evitar a construção de mensagens normativas e de caráter imperativo; buscar a mudança do comportamento através do diálogo e da reflexão sobre a origem dos problemas e a forma de intervenção, tanto no nível individual quanto no coletivo, na conquista da solução;

c) instrumentalizar a população do ponto de vista técnico e conceitual, visando identificar os seus problemas, de forma a capacitá-la para a análise das causas e conseqüências em sua prática cotidiana;

d) abordar os temas de saúde numa perspectiva educativa, que considera o universo simbólico e cultural da população;

e) evitar formulações teóricas e abstratas, bem como o uso de termos técnicos incompreensíveis, na sua maioria, para o público-alvo;

f) estimular a participação da população nas ações decisórias do Sistema Único de Saúde - SUS, através da ação dos conselhos municipais de saúde, considerando que cada pessoa é um agente do processo de luta pela melhoria da qualidade de vida de sua família e de sua comunidade;

g) mostrar quais são os meios e ações que a população pode utilizar para se prevenir contra as doenças. 
Com base nesses critérios, as mensagens do programa deveriam ser facilmente compreensíveis, adequadas do ponto de vista da cultura da região, práticas, relevantes e sintéticas, além, é claro, de tecnicamente corretas e positivas.

Outro elemento importante nessa estratégia era romper a unilateralidade, muito comum em produções centralizadas, estabelecendo um canal de comunicação com os ouvintes. Para tanto, ficou definido que o Saúde no ar abriria espaço à participação do público, realizada através de cartas. Quem tivesse qualquer dúvida sobre determinado tema de saúde deveria, para ser atendido, escrever para a produção, em Brasília, cujo endereço seria sistematicamente divulgado em todas as edições do programa.

\section{Público-alvo}

A eficácia da proposta dependia da definição do público-alvo, o que determinaria, conseqüentemente, o tipo de emissora para a veiculação. O público-alvo escolhido era constituído por mulheres de baixa renda, em idade reprodutiva (15 a 39 anos), e donas de casa. O pressuposto dessa escolha é que tradicionalmente cabe à mulher a tarefa de educar e cuidar dos filhos, principalmente na região nordestina e entre famílias de baixa renda, onde o homem ainda é o provedor. A mulher é o alvo preferencial por estar mais disposta a receber e aceitar informações que vão contribuir para a melhoria da qualidade de vida de sua família. Ela é, ainda, o agente transformador da realidade cotidiana, no nível doméstico.

Para definir o espaço de veiculação foi considerado que a audiência de rádio é maciça nas áreas mais pobres. Segundo dados da Marplan (1994), $92 \%$ dos nordestinos sintonizam alguma emissora de rádio. Entre as mulheres, esse índice éde $91 \%$, com público mais expressivo exatamente nos níveis socioeconômicos C, D e E. Ainda de acordo com a pesquisa, os níveis $\mathrm{C}, \mathrm{D}$ e E, em especial as donas de casa, têm preferência pelas emissoras AM, enquanto que as FMs têm maior audiência nas capitais e entre o público jovem ${ }^{11}$.

Foi considerado que não bastava apenas atuar no campo das emissoras AM, considerando as 400 estações existentes, pois as mesmas não cobrem todos os municípios da região Nordeste. Por isso, optou-se por incluir no rol de veiculação os serviços de altofalantes, que, em muitas cidades, são o único canal de comunicação dos moradores. Geralmente, os serviços estão sob controle de associações de moradores, igrejas católicas e protestantes, clubes de serviço e sindicatos, situados em pontos estratégicos de grande movimentação.

\section{ESTRATÉGIAS OPERACIONAIS}

Estabelecido o marco teórico-conceitual no qual o programa Saúde no ar estava inserido, fez-se necessário colocar em prática uma estratégia de ação no sentido de conquistar a adesão das emissoras de rádio e serviços de alto-falantes. Inicialmente, todas as 400 emissoras AM e 800 pontos de alto-falantes cadastrados ${ }^{12}$ receberam uma correspondência, um mês antes da distribuição da primeira edição do programa, na qual o Ministério da Saúde informava sobre a proposta de produzir um programa educativo sobre saúde, com qualidade técnica compatível com a programação das emissoras comerciais, $\mathrm{e}$ que ainda seria permitido aos integrantes do pro- 
jeto buscar patrocínio no comércio ou na indústria local. Na oportunidade, foi solicitado que se pronunciassem sobre $o$ assunto.

Nesse comunicado estavam evidenciadas três propostas decisivas na conquista de apoio à iniciativa:

1. a transmissão do programa não era obrigatória, ou seja, não fazia parte do horário destinado por lei ao governo para veiculação de mensagens oficiais, conforme prevê o Código Brasileiro de Telecomunicações;

2. o programa poderia ser comercializado pela emissora e veiculado em qualquer horário;

3. havia o compromisso de que fosse apresentado um produto de qualidade com periodicidade regular, sem fugir ao estilo da programação das emissoras.

As respostas chegaram rápido. Antes do lançamento, em agosto de 1994, 100 emissoras e 80 serviços de alto-falantes manifestaram interesse em conhecer o Saúde no ar e diziam ter disponibilidade para agendar sua veiculação.

Apesar de, inicialmente, o número de interessados ter sido inferior ao dos $1.200 \mathrm{ca}$ dastrados, a coordenação do IEC decidiu enviar o programa a todos. A intenção era ampliar a adesão ao projeto, pela demonstração do produto.

Paralelamente ao contato com as emissoras, foi iniciado um treinamento a distância das equipes de IEC nos estados, capacitandoas a realizar entrevistas com técnicos de saúde. A produção de um programa de rádio era algo novo para essas equipes, ou seja, uma tarefa a mais a ser agrupada à sua rotina de trabalho, para a qual a maioria, exceto os jornalistas, não estava preparada.

$\mathrm{O}$ treinamento consistiu na distribuição de apostilas curtas, em linguagem simples e direta, contendo instruções para a realização de entrevistas, desde a técnica de manuseio do gravador até o modo de formular as perguntas.

A primeira pauta produzida pelas equipes evidenciou que a sistemática estava certa, mas carecia de aperfeiçoamento. Cada pauta enviada tinha, anexo, um comentário crítico sobre o trabalho anterior e uma nova apostila contendo instruções para superar os erros cometidos. $\mathrm{O}$ ajuste da equipe à qualidade técnica desejada foi obtido aos poucos, com saldo final bastante positivo: integração de todos os Estados ao projeto, cumprimento da pauta dentro dos prazos determinados e produção de entrevistas com qualidade sonora e de conteúdo.

\section{FORMATO E FASES ${ }^{13}$}

Vencidas as fases de contatos com as emissoras e treinamento da equipe de produção, restava trabalhar na construção do formato, estilo e apresentação do Saúde no ar.

A primeira definição foi a sua duração. Havia um entendimento, estabelecido a partir da análise da programação de emissoras comerciais, de que dificilmente os radiodifusores aceitariam um programa com duração superior a 15 minutos. O motivo seria o risco da perda de agilidade e dinamismo do programa, pela sua natureza informativo-educativa, que poderia cansar o ouvinte, levando-o a mudar de estação. Por essa razão, ficou definido que o Saúde no ar teria 15 minutos de duração. 
O formato escolhido para o programa foi o de revista, com apresentação de dois locutores profissionais, pela sua natureza flexível. No rádio-revista é possível mesclar elementos informativos, dramáticos e musicais. É exatamente essa diversidade de recursos que o torna ameno e agradável, capaz de despertar a atenção do ouvinte.

O programa foi concebido para ter três blocos, separados por dois breaks contendo, ambos, uma chamada estimulando a participação do ouvinte através de carta e um spot ou jingle de 30 segundos, reforçando a mensagem principal do tema abordado. Os breaks foram propositalmente criados para permitir às emissoras a inserção de comerciais, caso obtivessem patrocínio local.

"Saúde no ar, um programa para quem acredita que prevenir é melhor do que remediar", slogan baseado num ditado popular, teve duas fases distintas quanto à utilização de recursos de produção.

Na primeira fase, de agosto de 1994 a fevereiro de 1995 , o programa apresentou recursos técnicos limitados, em face da escassez de recursos financeiros. Cada edição abordava em profundidade apenas um tema de saúde, com a apresentação de entrevistas gravadas nos Estados e músicas especialmente produzidas por cantadores populares, além de vinhetas que entrecortavam o texto (conselho de amigo, prevenir para não remediar, você sabia? e dicas de saúde). Apesar da limitação de recursos, o programa se diferenciava dos demais pela forma coloquial, descontraída, sem prejudicar a transmissão do conteúdo técnico.

Sem fugir ao estilo que o consagrou, o Saúde no ar teve em sua segunda fase, abril de 1995, novos atrativos. Foram produzidas vinhetas cantadas para a abertura, passagem, encerramento e quadros ${ }^{14}$. Cada edição abordava dois temas, sempre relacionados à saúde

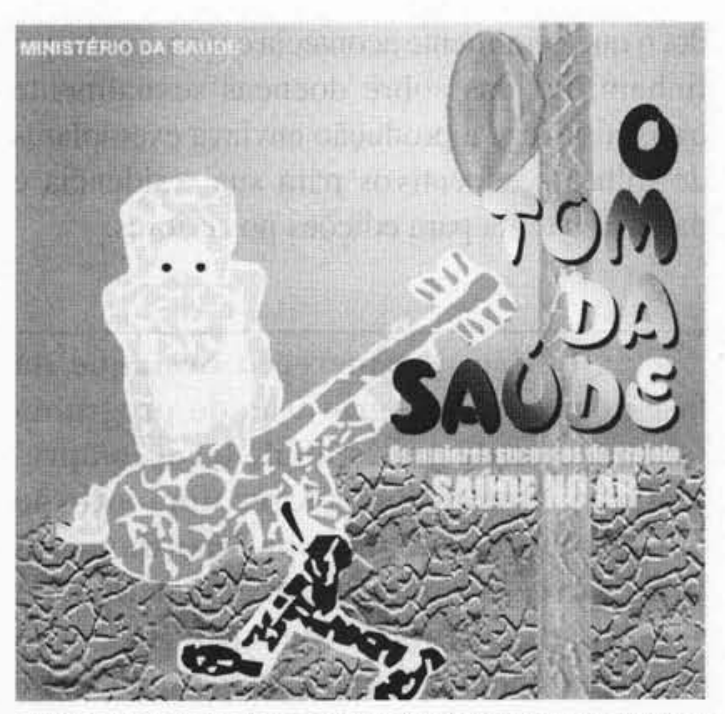

O Projeto encarregou-se também de editar um CD-Rom com os maiores sucessos musicais da programação.

da mulher e da criança. O tema principal era apresentado mediante uma pequena dramatização com atores profissionais, que retratava o modo como o problema em questão é vivenciado pela comunidade. Em seguida, técnicos de saúde da região contextualizavam o problema e apresentavam medidas preventivas. Havia, ainda, um quadro fixo sobre alimentação alternativa com dicas e recomendações sobre consumo de alimentos típicos da região, acessíveis à população pelo seu baixo custo e recomendados por seu valor nutritivo.

$\mathrm{Na}$ perspectiva de preservar o caráter regional, foram mantidas, nessa segunda fase, as participações de cantadores populares, inclusive com diversificação de ritmos, passando pelo forró, samba de coco e moda de viola.

Em ambas as fases havia espaço para responder às dúvidas dos ouvintes que enviavam cartas à produção. Em geral, era divulgado o nome do ouvinte, a sua dúvida e, em seguida, um profissional de saúde respondia a pergunta formulada. Se ele não desejava ser identifica- 
do, o que geralmente acontecia com aqueles que tinham dúvidas sobre doenças sexualmente transmissíveis, a produção enviava exemplares de folhetos educativos para sua residência e pautava o tema para edições posteriores.

Questão que mereceu destaque na fase de produção e gravação do programa foi a escolha de um estilo de locução/apresentação. Optou-se por fazer uma locução que não imitasse o modo de falar da população, ou seja, com sotaque regional. Há uma grande diversidade de sotaques - o piauiense não fala como o pernambucano $\mathrm{e}$ nem como o baiano - difícil de ser abarcada em duas vozes. Qualquer tentativa de colocá-la em prática se revelaria mais uma imitação do que um elemento de aproximação e identidade com o universo cultural.

Decidiu-se, portanto, pelo uso de palavras regionais, denominação de coisas, objetos, alimentos e situações de forma popular, Бem como uma locução livre de maneirismos.

Em relação à dramatização das situações, realizada pelos autores, foi adotado o mesmo procedimento. Procurou-se dar veracidade às cenas e às situações, sem imitação de sotaques.

\section{DISTRIBUIÇÃO ÀS COMUNIDADES}

Qual o meio mais prático e seguro para fazer com que o programa Saúde no ar chegasse às emissoras de rádio e serviços de altofalantes? Essa indagação, que atormentava a coordenação do projeto, teve várias respostas. A primeira seria utilizar o canal da Embratel, no qual é transmitido diariamente o programa A voz do Brasil. Como o programa é obrigatório, todas as emissoras do Brasil precisam sintonizar esse canal, com pelo menos $15 \mathrm{mi}$ nutos de antecedência, e aguardar o sinal de transmissão. A idéia era ocupar esse espaço para gerar o programa e solicitar aos interessados que o copiassem para posterior veiculação. No entanto, essa idéia foi abandonada por vários motivos. Entre eles a baixa qualidade do som, o fato de que a transmissão é para todo o Brasil e o risco de a emissora não conseguir fazer a cópia completa.

$\mathrm{O}$ meio mais seguro de fazer com que o programa atingisse a meta pretendida era gravá-lo em fita cassete para envio pelo correio. Decidiu-se que as emissoras receberiam, mensalmente, duas fitas: uma contendo quatro edições do programa e outra com quatro spots utilizados nos breaks. O uso de duas fitas tinha um propósito. Caso a emissora não desejasse veicular o programa, poderia inserir em sua programação normal os spots. Isto propiciava ao radiodifusor uma outra opção de adesão ao projeto.

Ao longo do tempo, a expedição via correio acabou expondo falhas. Muitos destinatários reclamavam do atraso na entrega, bem como o fato de que muitas caixas chegavam abertas e com ausência de uma fita.

\section{RESULTADOS DA EXPERIÊNCIA}

O primeiro sinal de que a experiência estava dando certo foi a adesão das emissoras e dos serviços de alto-falantes. Na terceira edição do programa foi solicitado aos destinatários que informassem o dia e horário da veiculação do Saúde no ar. O primeiro levantamento revelou que 156 emissoras ( $40 \%$ do total) e 120 alto-falantes ( $15 \%$ do total) divulgavam o programa. O resultado foi avaliado de forma positiva considerandose a falta de tradição do brasileiro em responder cartas. Constatou-se, através do monitoramento das coordenações de IEC em alguns Estados, que 
o programa era veiculado em emissoras que não responderam a correspondência inicial. Esta talvez tenha sido a maior dificuldade do projeto: ter um quadro preciso e concreto da veiculação do Saúde no ar. Dada a extensão de sua área de abrangência, a ausência desse quadro cria dificuldades para o monitoramento de campo ${ }^{15}$, bem como irregularidade na forma de comunicação entre as emissoras e a coordenação de IEC.

Outro elemento agregado à avaliação foram as cartas dos ouvintes enviadas à produção. No período de existência do projeto foram recebidas $\mathbf{5 7}$ cartas que revelaram a aceitação do público, o acerto no formato escolhido, a importância das informações transmitidas e o fato de as mesmas estarem diretamente relacionadas ao seu cotidiano.

Abaixo, são transcritos alguns trechos extraídos das cartas, reveladores da apropriação do conteúdo transmitido:

"Escrevo-lhes para parabenizar pelo programa Saúde no ar, pois é muito importante para auxiliar as mães numa melhor alimentação para seus filhos".

Marinalva Pereira da Silva, São Francisco do Maranhão, MA.

"Em primeiro lugar gostaria de agradecer por vocês estarem nos dando oportunidade de conhecermos melhor a riqueza de nossa região... Pois eu sou pobre e como vocês sabem às vezes a gente tem até a necessidade de comer comida alternativa, mas por falta de informação desperdiçamos muita coisa".
Maria Lúcia de Andrade, Nossa Senhora do Glória, SE.

"Este programa é ótimo para as famílias, principalmente, fortificando todas as orientações dos agentes de saúde. Admiro muito este programa, estou atenta a toda informação!"

Ana de Fátima Pereira Gomes. Itapagé, $\mathrm{CE}$.

"Gostei muito de ouvir as mensagens sobre saúde que a equipe produziu, principalmente pelo linguajar acessível e precisão das informações. Até pedi ao responsável pela divulgação das mensagens em nossa cidade, para que me fizesse uma cópia, pois irei utilizá-la nos encontros de líderes da Pastoral da Criança, atingindo assim mais pessoas interessadas no assunto".

José Carlos Guerra, coordenador paroquial de Mortugaba, BA.

"Gostaria de saber como se pega Aids. Tem vacina? Como é a prevenção? Dizem que no beijo e aperto de mão, abraço, beber água no mesmo copo não se pega Aids. É verdade?? ...Tenho 17 anos, não sei muito sobre tipos de doenças, principalmente a Aids..."

Wilma A. da Silva, Jacobina, BA.

"Éatravés da Rádio Currais Novos que escuto todos os domingos, às $11 \mathrm{~h}$, este ótimo programa e gosto muito. Por isso resolvi escrever para pedir muitas informações sobre saúde e ficarei muito feliz em receber resposta. Olha, quero saber tudo sobre remédios caseiros e de primeiros socorros de queimaduras de fogo, sol, afogamentos e mordidas de insetos venenosos..."

Francisca das Chagas Silva, Currais Novos, RN.

15. A dificuldade, nesse caso em particular, é a ausência de pesquisas de audiência no interior do país, face aos elevados custos necessários para sua realização. O Ibope, maior instituto de pesquisa do país, atua apenas em 15 capitais e só realiza pesquisa no interior sob encomenda. Sendo assim, resta o contato via carta como elemento básico de comunicação para o estabelecimento de qualquer avaliação em matéria de rádio. 
"Não os conheço, mas preciso de pessoas bem informadas, pessoas amigas que possam ajudar um jovem, que tem 26 anos e que mora numa cidade pequena e pacata, do interior de Sergipe. Concluí o segundo grau na capital, mas nem mesmo a cidade grande fez com que eu perdesse o meu jeito pacato de ser. Todavia, aprendi a ser mais comunicativo com as pessoas próximas e distantes. Aqui na minha cidade há um serviço de som que pertence à prefeitura. Foi por ele que consegui o endereço de vocês. Por isso resolvi escrever, pois necessito de respostas para me prevenir contra uma doença muito comum entre os homens: o câncer de próstata".

N.S., Divina Pastora, SE.

Sem dúvida alguma, as cartas são instrumentos de avaliação do processo de comunicação, porque, em geral, refletem sentimentos, anseios e reações de aceitação ou repulsa da audiência frente às mensagens transmitidas. Porém, elas não são, neste caso, um indicador real e abrangente do ponto de vista numérico do impacto e da penetração do programa na região. Muitos ouvintes, talvez por timidez ou por dificuldade em copiar o endereço veiculado no programa, manifestavam sua opinião através de cartas ou visitas à emissora de rádio local, conforme foi constatado após contato com algumas delas. Por várias vezes foi solicitado às emissoras o envio dessas cartas, $o$ que, por motivos desconhecidos, não ocorreu.

\section{USOS DO PROGRAMA}

A análise das cartas recebidas também revelou uma forma muito particular de usos do programa por outro segmento: os agentes comunitários de saúde. Muitos deles passaram a utilizar o programa como elemento de motivação para discussão em palestras e reuniões educativas, promovidas em suas comunidades.

Registrou-se, ainda, uma forma muito especial de apropriação do produto pelos serviços de alto-falantes: veicular trechos do programa, intercalados com músicas da região.

Exemplo dessa apropriação foi registrado em Jurema, cidade no interior de Pernambuco, a $228 \mathrm{~km}$ de Recife. Em visita ao Ministério da Saúde, Narciso Severino da Silva, 31 anos, proprietário da rádio comunitária Cajurema, contou que essa forma de divulgação chamou a atenção dos ouvintes. Segundo ele, graças ao Saúde no ar houve considerável aumento do número de consultas médicas de crianças e mulheres. "Antes do programa de rádio muitas mulheres não sabiam o que era pré-natal, outras nem sequer haviam feito uma consulta médica durante a gravidez. Mas hoje o povo está mais esclarecido", disse Narciso, entusiasmado. Ele atribuiu ao projeto o crescimento dos índices de cobertura vacinal na cidade. Em 1994, apenas 33,92\% das crianças menores de cinco anos foram vacinadas contra a pólio. Com a divulgação do programa foram vacinadas, em 1995, na primeira etapa, $88,75 \%$ das crianças.

\section{AVALIAÇÃO DA EXPERIÊNCIA}

Após seis meses de distribuição do Saúde no ar a coordenação de IEC, em conjunto com a Faculdade de Comunicação da Universidade de Brasília, decidiu fazer uma pesquisa de avaliação e de veiculação do produto. Até o momento, as cartas recebidas dos ouvintes constituíam um instrumento de avaliação qualitativa, que não se caracterizava, em seu conjunto, como uma amostra representativa. Ha- 
via necessidade, portanto, de uma avaliação mais criteriosa, representativa de um universo, e que poderia ser realizada a baixo custo.

No período de vigência do projeto, foram realizadas duas pesquisas junto aos diretores de emissoras e serviços de alto-falantes. $\mathrm{Na}$ edição do programa, remetida em fevereiro de 1995 , os entrevistados receberam um formulário para preenchimento e posterior remessa via correio ou fax. As coordenações estaduais ficaram encarregadas de complementar a pesquisa, preenchendo o mesmo formulário após contato telefônico, pessoal ou por carta com a direção das emissoras de rádio.

O questionário distribuído continha questões abertas e fechadas, combinando pesquisa qualitativa e quantitativa - para obter maior profundidade nas respostas - abordava aspectos relativos ao conteúdo, formato, estilo, linguagem, dia/horário de veiculação e o impacto do programa perante a audiência.

$O$ resultado da primeira pesquisa foi bastante animador: o programa Saúde no ar possuía ampla aceitação junto aos radiodifusores e público-alvo. Das 400 emissoras, $23,97 \%$ responderam o questionário da pesquisa. Desse total, $91,4 \%$ dos entrevistados disseram que veiculavam o programa e $97,8 \%$ divulgavam o spot em sua programação normal, a maioria deles até cinco vezes ao dia. $\mathrm{Na}$ opinião de $57,4 \%$ dos pesquisados o programa e o spot são ótimos quanto ao conteúdo e apresentação; $40,4 \%$ os avaliaram como bons.

A maioria dos pesquisados $(\mathbf{7 9 , 7 \%})$ classificou como boa a repercussão dos produtos junto aos ouvintes. Esta opinião baseava-se em cartas, telefonemas recebidos e contatos mantidos com os ouvintes, os quais manifestavam satisfação e interesse em relação aos temas abordados.
$\mathrm{Na}$ opinião da maioria dos pesquisados, o conteúdo do Saúde no ar é rico em informação de benefício para a comunidade, principalmente para aquela que reside no campo, porque fornece orientações práticas sobre a prevenção de doenças. Alguns diretores de emissoras mencionaram que, em suas cidades, inúmeras donas de casa aplicavam em seu cotidiano as medidas preventivas relatadas no programa.

A linguagem acessível, de fácil compreensão, a qualidade da produção e da montagem técnica foram destacados pelos pesquisados como elementos que valorizavam o programa, garantindo seu espaço nas emissoras.

A segunda pesquisa foi realizada no mês de agosto de 1995 e teve o objetivo de avaliar o impacto das mudanças de formato da segunda fase. As mudanças foram aprovadas pela maioria das emissoras que responderam à pesquisa $(11 \%)$ e tiveram ampla aceitação junto ao público-alvo.

A totalidade dos pesquisados aprovou a dramatização utilizada para introduzir a discussão de um tema, haja vista que seu conteúdo tinha ligação direta com o cotidiano da população. A abordagem de mais de um tema em cada programação dividiu a opinião dos entrevistados: $39,16 \%$ consideraram que isso confunde o ouvinte; os restantes $60,84 \%$ aprovaram tal técnica por considerar que o recurso dá agilidade ao programa.

De acordo com a maioria, o programa cresceu em termos de qualidade de produção, constituindo-se num instrumento eficaz para a transmissão de conhecimentos e promoção da educação para a saúde. Mesmo não dispondo de pesquisa de audiência de institutos renomados - como o Ibope - em seus municípios, a maioria das emissoras $(58,6 \%)$ considera boa a repercussão do programa junto ao público. Elas baseiam sua opinião em cartas, telefonemas recebidos e contatos mantidos com os ouvintes que solicitam reprise de programas e tecem comentários sobre os temas abordados. 


\section{LIÇÕES APRENDIDAS}

$\mathrm{O}$ relato desta experiência demonstra claramente que ainda é possível desenvolver, pelo rádio, um projeto institucional de educação e comunicação em saúde, desde que sejam considerados os seguintes aspectos:

a) é fundamental que a definição do referencial teórico-conceitual seja totalmente distanciada das experiências que utilizaram o rádio para educação formal ou para difusão de uma cultura elitista;

b) romper a unilateralidade que tem marcado as ações centralizadas, criando formas de participação do público no programa;

c) ter a regionalização como meta: ela é o caminho para a aproximação do universo cultural e simbólico do público, o que pode ser feito utilizando-se a música, modo de falar da população e abordagem dos problemas da forma como são vividos na região. Significa, basicamente, incorporar ao produto a dimensão do popular;

d) definir claramente o público e a área de abrangência que se pretende atingir. Ter em mente que a audiência do meio rádio é segmentada, dada a sua pulverização. Não se pode atingir todo um público através de uma única emissora, haja vista as inúmeras implicações na determinação da linguagem, estilo e formato do produto;

e) conquistar o apoio das emissoras para veiculação gratuita do programa, sem imposição legal de dia e horário determinados. Para isso, é importante apresentar um produto com qualidade técnica, formato e linguagem compatíveis com a rádio comercial. Por possuir tais qualidades, pode e deve ser patrocinado; f) estabelecer uma relação profissional com as emissoras quanto à entrega do produto nos prazos, com regularidade. Os atrasos geram perda de credibilidade do produtor e levam a emissora a repetir programas anteriores. Situação essa que conduz à queda da audiência. Deve-se ter sempre em mente que rádio é uma empresa que, para se manter no mercado, precisa conquistar tanto os ouvintes como os patrocinadores;

g) dar à produção um caráter profissional. Buscar no mercado o que há de melhor em locução, operação de áudio, estúdio de gravação e produção de vinhetas. Para ter boa aceitação, o trabalho precisa estar limpo do ponto de vista estético e impecável quanto ao estilo;

h) por fim deve ser feita uma constante avaliação do produto, com o objetivo de corrigir eventuais falhas. Significa estar sempre aberto à mudança de rumos, face às críticas. Nada melhor do que se guiar pela voz do ouvinte: ela é sábia e sincera.

Cada edição do Saúde no ar foi um aprendizado quanto à criação de formas e estratégias para transmitir informações vitais. A descoberta de novos modos de educar pelo diálogo e pela compreensão, respeitando-se sempre a inteligência do ouvinte. As cartas recebidas deram apoio e incentivo à continuidade do projeto, indicadores fiéis de sua aceitação.

Sem dúvida, o rádio ainda é o meio de comunicação massivo que demanda poucos recursos de produção e veiculação e, por isso, deve fazer parte das estratégias de educação e saúde. É certo que, isoladamente, o meio tem eficácia limitada em termos educativos, mas pode ser potencializado se integrado a outros instrumentos de educação não-formal. 
Resumo: O artigo destaca a importância do uso do rádio na veiculação de programas de educação em saúde. A iniciativa do Ministério da Saúde, através de sua Coordenação de Informação, Educação e Comunicação, em parceria com a Faculdade de Comunicação da Universidade de Brasília, produziu, entre 1994 e 1995, uma série de programas radiofônicos de educação em saúde voltada a comunidades carentes do Nordeste. A autora destaca a preocupação do projeto em não repetir erros do passado na concepção, formatação e veiculação de programas educativos pelo rádio. Discute sobre as formas de conseguir a adesão das rádios comerciais e da comunidade na veiculação de projetos institucionais, bem como a importância de se abrir um canal de comunicação efetivo com a comunidade. Os programas temáticos, em formato de revista, tinham 15 minutos de duração, com breaks e spots que permitiam maior liberdade às emissoras na forma de veiculação do projeto. $\mathrm{Na}$ avaliação, destacou-se a importância de uma produção profissional, sintonizada com as necessidades da comunidade e com as exigências próprias da linguagem do veículo. Concluiu-se que a maioria das emissoras veiculadoras dos programas consideraram a experiência positiva, tendo em vista o sucesso entre os ouvintes.

Palavras-Chave: rádio, Saúde no ar, comunidade, Nordeste, rádio comercial, serviço de alto-falante, Ministério da Saúde
Abstract: The article stresses the importance of using the radio to transmit health education programs. The Health Ministry initiative, through the Information Coordination, in a partnership with the Brasília University Communications College, produced, between 1994 and 1995, a series of radio programs on health education aimed at poor communities in Northeastern Brazil. The author stresses the project's concern in not repeating previous errors in the conception, formatting and transmission of educational programs on the radio. It discusses how it is possible to get commercial radios and the community to adhere to institutional project transmissions and it deals with the importance of opening an effective communication channel with the community. Thematic programs, in the magazine format, lasted 15 minutes and had breaks and spots that allowed for the stations to have greater freedom to air the project. In the evaluation stressed the importance of professional production, in tune with the community needs and with the vehicle's own language demands. It was concluded that most stations that aired the programs considered the experience positive since they were successful among the listeners.

Key words: radio, Health on the air, community, northeast, commercial radio, loudspeaker service, Health Ministry 